\title{
SEEDER EQUIPPED WITH SEEDS DELIVERY MECHANISM DEPENDING ON AN OSCILLATING MOTIVATION UNIT
}

*Ismail, Z. E.

\section{ABSTRACT}

Seeder equipped with seeds delivery mechanism depending on an oscillating motivation unit was constructed and tested under indoor experiments. The main components of investigated prototype are; seeds delivery mechanism equipped with oscillating unit, metering device and mobile trolley as power unit. On the base of a corn fertilizer unit a tray was conducted to plant seeds of Phaseolus. Four seeds delivery speeds $(S D S)$ of $0.4 ; 0.5 ; 0.6$ and $0.7 \mathrm{~m} / \mathrm{s}$ with three hole span (HS) of 50, 100 and $150 \mathrm{~mm}$ and three different of the delivery tubes lengths (TL) of 300, 400 and $500 \mathrm{~mm}$ were identified as independents variables. The influence of a reciprocating motivation unit on the seeds distribution evaluated by calculating seeds miss index (MI), multiples index (DI), quality of feed index (FI) and precisions index (PI) in spacing for kidney bean (Phaseolus Vulgaris) seeds. The results indicated that increasing the seeds delivery speed 1.75 times MI increased by about 3.6 times at $H S=150 \mathrm{~mm}$. The appropriate relation was found at $S D S=0.5 \mathrm{~m} / \mathrm{s}$ and $H S=100 \mathrm{~mm}$. Also, the data revealed a direct proportion between DI and each of SDS and TL. The feed index (FI \%) recorded the highest values (95.9\%) at SDS of $0.5 \mathrm{~m} / \mathrm{s}$ and HS of $150 \mathrm{~mm}$. For example by increasing the SDS 1.5 times FI \% decrement by about 0.9 times.

\section{NTRODUCTION}

dvancement in precision planting has come with the
development of punch seeders equipped with plungers, dibbles
or spades. An early type of punch seeder was a plunger type which has been studied experimentally on spacing and depth control (Sawant, 1972; Gebresenhet and Jonsson, 1992 and Janelle et al., 1993).

* Prof. of power technology and farm machinery, Agric. Eng. Dept. Fac. of Agric.

Mansoura Univ. Email: ebrahimzi@yahoo.com

Email: $\underline{\text { Ismailze221@mans.edu.eg or ebrahimzi@yahoo.com }}$ 
A development in precision planting which could be applied to various types of crops is the spade-punch or revolving spade seeder and the design concept was called the revolving spade seeder which was the application of a new hole forming system (Shaw and Kromer, 1987 and Guler, 2005).

Molin et al. (1998a) projected a punch seeder with pneumatic seed meter for no-till consisting on wheel with 15 punches distributed around a metallic ring. The punches, without relative movement, with the rotation make a vertical angle of $22^{\circ}$ and an angle of $7^{\circ}$ with the longitudinal axis. After that, Gratton and Tessier (2003) and Molin et al. (2002) built a second prototype with the objective of testing the possibility of changing population of corn seeds by changing the spacing among plants. The project was based on the previous prototype, for which three wheels were built, with different diameter, varying the length of the punches. Ismail (2004) and Ismail et al. (2009) describes the specification of requirements and the functionality, of a new mechanism of punch seeder system depending on the four bar mechanism to transfer the seeds into soil.

The aim of Ismail's work is to manufacture and construct the investigated seeder, studies the effect of oscillating tube mechanism on the seeds distribution and to determine the factors that realizes the best operation condition. Ismail (2011) focused on some of the questions related to punching seeder performance with changes in seed distribution and oscillating tube of the punch mechanism. He indicated that the smallest delivery tube length $(350 \mathrm{~mm})$ that gives best results at $0.39 \mathrm{~m} / \mathrm{s}$, with a quality of feed index of $95.1 \%$ and precision of $3.92 \%$. The multiples index and miss index, not always significant, as complementary of quality of feed index, were the lowest at $0.39 \mathrm{~m} / \mathrm{s}$. This was recommended with Heege (1993) and Ryu, and Kim (1998).

A punch seeder may offer better seeding performance than conventional seeders for no-tillage conditions because it moves a minimum amount of soil and residue and offers precision in seed spacing. The minimum of research has been completed to overcome some limitations that these machine concept offers, specifically mechanisms to change population rate. Plant population stands have been widely studied. Local 
recommendations for corn populations are available (Karayel et al. 2006, Ess et al. -2005, Gratton and Tessier 2003, Ozmerzi and Topakci 2002, Schueller, 1992 and Solie 1991).

So, the main aim of this work is to improve and to control the seeding performance of kidney bean (Phaseolus Vulgaris) by improving the seed delivery mechanism in motivator seeder using the reciprocating mechanism.

\section{MATERIALS AND METHODS}

\section{Preparing Delivery Seeder}

The main components of delivery prototype are; seeds delivery mechanism, metering device and mobile trolley (figure-1):-

- The dominant element of seeds delivery mechanism is oscillating tube mechanism that consists of a four-bar mechanism. It was design to realize the vertical straight-line displacement. The displacement stroke was regulated with moving oscillating transmission (figure-2).

- Seed metering system, is a fertilizer unit of corm seeder. It's used as a tray to Phaseolus planting. The unit is sit at the delivery seeder prototype and connected to the iron frame. The Phaseolus of seeds fall into the cells on the edge and dropped inside the oscillating tube mechanism. The seed holding number is regulated to achieve the required number by changing the rotational speed of feeding unit.

- The mobile trolley is considered the base at which the investigated feeding device fixed on the soil bin frame. The motion was supplied to trolley by close transmission wire system. Four bearing were fixed on the rod of trolley to over com the trolley resistance. The case of bearing was designed to easy run on the two parallel rail rods. The test-trolley was powered by electrical motor of $15 \mathrm{~kW}$, which transmit the motion to the trolley by two individual reductions gears to simulate the speed of the planting seeds (Ismail-2004).

\section{Delivery seeder calibration}

Indoor, the delivery seeder operated using electrical motor of $0.33 \mathrm{HP}$. The prototype work divided into three steps:

1) Drilling, the delivery tube penetrated into the soil by the action of the rotating counter weight (felly wheel) on the crank shafts for the four bar mechanism that pushing the free part of the delivery 
system. Consequently, the seeder provided impact force in this step.

2) Seeding, it was done by harmonizing the action of the roller mechanism motion and delivery seeder transmission motion when the seeds from the hopper were dropped into the holes through the metering device.

3) Closing, the holes are closed by pressing-wheel with diameter of $300 \mathrm{~mm}$, width of $100 \mathrm{~mm}$ and air pressure of 28 bars. It was located behind the reciprocated delivery seed tube.

The hole to hole spacing was adjusted from 50,100, and $150 \mathrm{~mm}$ by changing the reciprocating crank radius with different delivery tube lengths, represented 500, 400, and $300 \mathrm{~mm}$ respectively. The oscillating tube mechanism was regulated to create hole in soil with $12 \mathrm{~mm}$ diameter and $5-7 \mathrm{~mm}$ depth regarding to seed delivery speed.

\section{Seed variety}

The kidney bean was tested and evaluation by the investigated delivery seeder. The kidney bean (Phaseolus vulgaris) used in the study was obtained from a local market. The samples were cleaned manually to remove all foreign materials such as dust, dirt, stones and chaff as well as immature and broken grains. The main specification of Phaseolus vulgaris, Geza-6 variety were seed length $\mathrm{L}=16.787 \mathrm{~mm}$, seeds width $\mathrm{W}$ $=8.755 \mathrm{~mm}$, seeds thickness $\mathrm{T}=5.056 \mathrm{~mm}$, mass of 1000 seeds $\mathrm{M}=$ $584.35 \mathrm{~g}$, at moisture content dry basis $\mathrm{MC}=12.875 \%$.

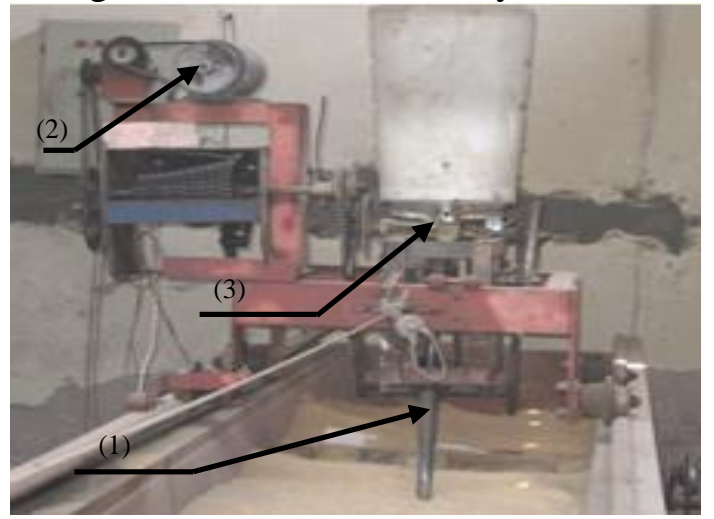

1. Oscillating tube mechanism

2. Input power

3. Metering device

4.Oscillating transmission

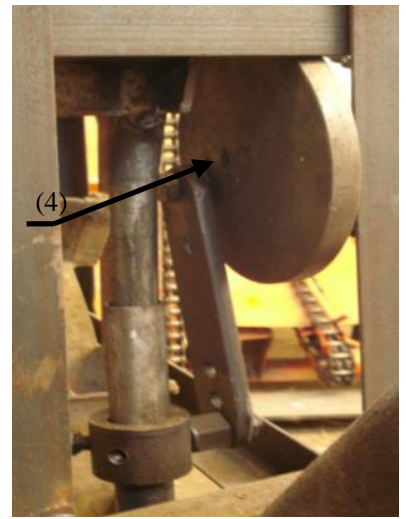

Figure (2): Oscillating motivation

Fig. 1: The investigated delivery seeder (Ismail, 2009) 


\section{The dependent and un-dependent variables}

Indoor experiments were based on for four seeds delivery speeds of 0.4; $0.5 ; 0.6$ and $0.7 \mathrm{~m} / \mathrm{s}$ and with three hole spans of 50, 100, and $150 \mathrm{~mm}$. The evaluation was based on the measurement of distances between the seeds falling from the feed device. In delivery seeder system, the ratio between the revolution number of feeding disk and the oscillation number of delivery tube were regulated to maintain synchronization between seeds span and seeds drop from measuring device.

Indoor experiments were replicated three times per each treatment of the evaluation delivery seeder. To determine the effect of the oscillating tube radii and the seed delivery speed under three different of the delivery tube lengths $(300,400$ and $500 \mathrm{~mm})$ on delivery seeder performance. The data were statistically analyzed with program Minitab 17. The undependent variables were, namely, miss index, multiples index, feed index, and precisions in spacing.

\section{Miss Index of Seed (MI, \%)}

The miss index "MI" is the percentage of spacing greater than 1.5 times the set planting distance "S" in cm divided on the theoretical number of grain per certain measured spacing.

$$
\mathrm{MI}, \%=\frac{\mathrm{n}_{1}}{\mathrm{~N}} \times 100
$$

\section{Multiples index of seeds}

The multiple index "DI, \%" is the percentage of spacing that are less than or equal to half of the set plant distance "S" in cm divided on theoretical number of grain per certain measured spacing.

$$
\text { DI, } \%=\frac{\mathrm{n}_{2}}{\mathrm{~N}} \times 100
$$

Where:

$$
\begin{aligned}
& \mathrm{n}_{1}=\text { Number of spacing }>1.5 \mathrm{~S} \\
& \mathrm{n}_{2}=\text { Number of spacing } \leq 0.5 \mathrm{~S} . \\
& \mathrm{N}=\text { Theoretical number of grain per certain measured spacing } \\
& \mathrm{S}=\text { the theoretical set planting distance }
\end{aligned}
$$

Feed index quality (FI, \%)

The uniformity of the seed in the row could be considered as the third indicator for the seed disposing performance. It was estimated by 
calculating the seed miss index and the seed multiples index. Then the percentage of the quality of feed index in the row can be calculated as follows:

$$
F I, \%=100-(M I, \%+D I, \%)
$$

Seed precision index (PI, \%)

Precision (PI, \%) is the coefficient of variation of the spacing between the nearest plants in a row that are classified as singles after omitting the outliers consisting of misses and multiples. The analysis of variances test was used to analysis the obtained data under different variables.

\section{Factors affecting miss index \\ RESULTS AND DISCUSSION}

During indoor experiments, three main parameters are affecting percentage of Phaseolus miss index (MI, \%) mainly, seeds delivery speed (SDS, $\mathrm{m} / \mathrm{s}$ ), delivery tube lengths (TL, $\mathrm{mm}$ ) and hole span (HS, $\mathrm{mm}$ ). Figure (3) showed the relationship between seed delivery speed $(\mathrm{m} / \mathrm{s})$ on seeds miss index (\%) under different hole span ( $\mathrm{mm})$. The surface plot of the above relation indicated that seeds miss index (MI, \%) decreased as increasing seed delivery speed (SDS, $\mathrm{m} / \mathrm{s}$ ) until low level at SDS of $0.5 \mathrm{~m} / \mathrm{s}$ and after that the miss index rapidly increased. The above note was found during regularize the delivery prototype to create hole span (HS) with 50 and $150 \mathrm{~mm}$ and vice versa at $\mathrm{HS}=100 \mathrm{~mm}$. The miss index recorded the highest values at $\mathrm{SDS}=0.6 \mathrm{~m} / \mathrm{s}$ and $\mathrm{HS}=50 \mathrm{~mm}$. For example, increasing the seed delivery speed 1.75 times the miss index increased by about 3.6 times at hole span of $150 \mathrm{~mm}$. The appropriate relation was found at $\mathrm{SDS}=0.5 \mathrm{~m} / \mathrm{s}$ and $\mathrm{HS}=100 \mathrm{~mm}$.

The surface plot of miss index (MI, \%) as affected by delivery tube length (TL) at different seed delivery speed (SDS) is illustrated in figure (4). Generally, the mentioned data revealed a direct proportion between delivery tube length (TL) and miss index (MI, \%). While, the same trend observed with seeds delivery speed. Mostly, any increment in seeds delivery speed (SDS) resulted in increment in grains miss index (MI, \%) with other words, increasing SDS resulted in increment in MI as directly proportion. For example, increasing the TL 1.67 times the MI increased by about 1.89 and 2.22 times at increasing SDS from 0.4 to $0.5 \mathrm{~m} / \mathrm{s}$. But, 
increasing SDS from 0.6 to $0.7 \mathrm{~m} / \mathrm{s}$ the MI decreased by about 2.00 to 1.46 times at increasing the TL from 300 to $500 \mathrm{~mm}$.

The fit regression type of data analysis was applied to relate the change in seed miss index as a relation with seed delivery with neglect the effect of hole span and delivery tube length was found as:

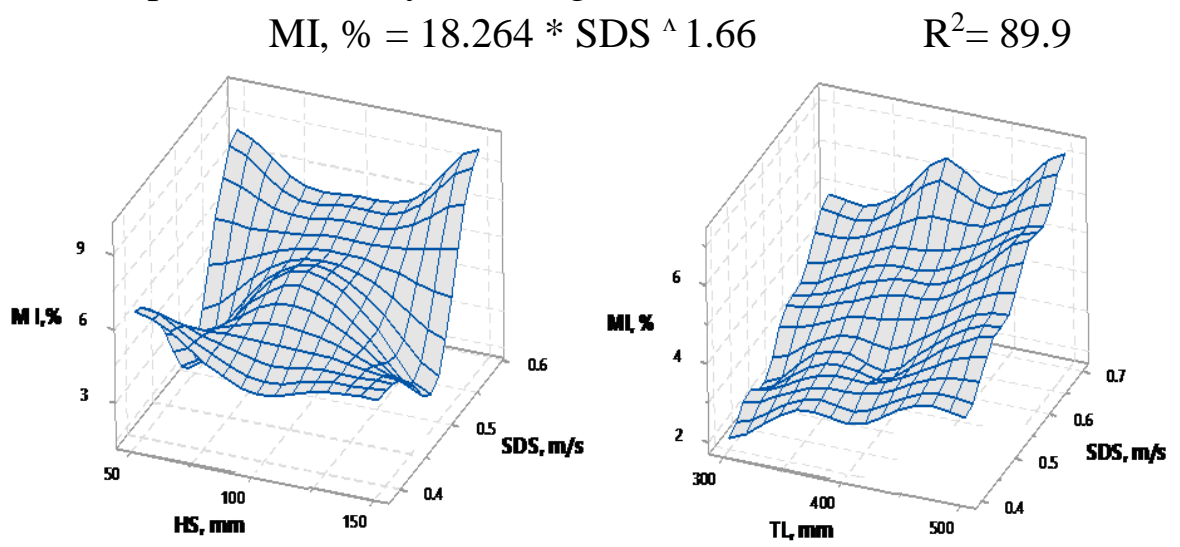

\begin{tabular}{l|l|l} 
Figure (3): Surface plot of miss index vs & Figure (4): Surface plot of miss index vs
\end{tabular} delivery speed and hole span delivery speed and tube length

Also, fit regression type of data analysis was applied to relate the change in seed miss index as a relation with hole span was:

$$
\text { MI, \% }=4.97 * \mathrm{HS}^{\wedge} 0.031 \quad \mathrm{R}^{2}=97.9
$$

Equation (1) indicated that increment the SDS from 0.4 to 0.5 increased MI from $3.99 \%$ to $5.78 \%$ and by increasing the HS from 50 to $100 \mathrm{~mm}$ (equation 2), the MI increased from $5.61 \%$ to $5.73 \%$. Previous result shows that the effect of seeds delivery speed is greater that the effect of hole span on miss index.

\section{Factors affecting multiples index}

The investigated prototype was tested and evaluated laboratory on the bases of multiples index indicator (DI, \%). The typical obtained data were illustrated in figure (5) under different hole span (HS) and different tubes length (figure 6).

Figure (5) showed the relationship between seed delivery speed $(\mathrm{m} / \mathrm{s})$ on seeds multiple index $(\%)$ under different hole span $(\mathrm{mm})$. The surface plot of the above relation indicated that during seed delivery speed increased from 4.0 to $0.6 \mathrm{~m} / \mathrm{s}$, the seeds multiple index decreased as increasing hole span until low level of hole span $(100 \mathrm{~mm})$ and after that 
multiple index rapidly increased. The deformation of increment and decrement of seed delivery speed at $0.4 \mathrm{~m} / \mathrm{s}$ was lower than that for rate of deformation at $6.0 \mathrm{~m} / \mathrm{s}$. The multiples index recorded the highest values at seed delivery speed of $0.6 \mathrm{~m} / \mathrm{s}$ and hole span of $150 \mathrm{~mm}$. For example by increasing the seed delivery speed 1.75 times multiples index increased by about 2.54 times at neglect the effect of hole span. The optimum relation was found at $0.5 \mathrm{~m} / \mathrm{s}$ seed delivery speed and $50 \mathrm{~mm}$ hole span and delivery tube length of $300 \mathrm{~mm}$.

The surface plot of multiples index as affecting by delivery tube length at different seed delivery speed was illustrated in figure (6). Generally, the mentioned data revealed a direct proportion between multiples index and each of seed delivery speed and tube length. Generally, any increment in seed delivery speed resulted in increment in seeds multiples index, $\%$. For example, by increasing the delivery tube length 1.67 times the multiples index increased by about 1.51 and 1.32 times at increasing seed delivery speed from 0.4 to $0.5 \mathrm{~m} / \mathrm{s}$. But by increasing seed delivery speed from 0.6 to $0.7 \mathrm{~m} / \mathrm{s}$ the rate of multiples index increasing but more than low rate by about 0.85 to 1.13 times.

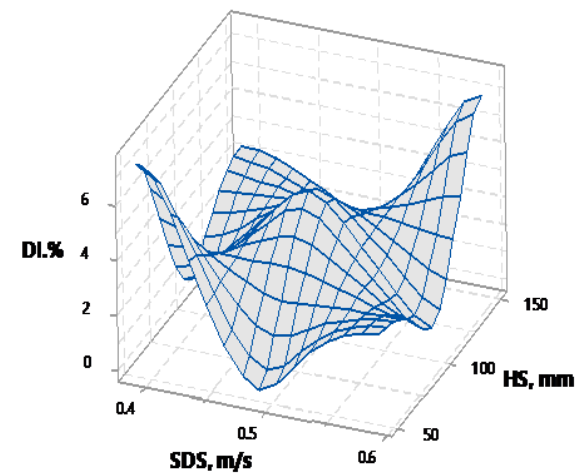

Figure (5): Surface plot of multiples index vs delivery speed and hole span

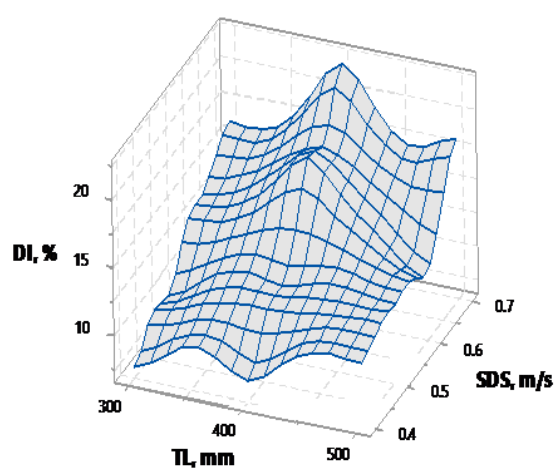

Figure (6): Surface plot of multiples index vs delivery speed and tube length

The fit regression equations of data, analysis were applied to relate the change in seed multiples index as a relation among seed delivery speed, tube length and hole span, were found as:

$$
\begin{aligned}
& \text { DI, } \%=30.43 * \mathrm{SDS}^{\wedge}(1.41) \\
& \mathrm{DI}, \%=2.53 * \mathrm{TL}^{\wedge}(0.280) \\
& \mathrm{DI}, \%=6.91 * \mathrm{HS}^{\wedge}(0.144)
\end{aligned}
$$


Equation (3) indicated that increment seed delivery speed from 0.4 to 0.6 the seeds multiples index increased from $8.32 \%$ to $14.81 \%$ and by increasing the delivery tube length from 300 to $500 \mathrm{~mm}$ (equation 4), the multiples index increased from 12.49 to $14.42 \%$. Also, by increasing the hole span from 50 to $100 \mathrm{~mm}$ (equation 5), the multiples index increased from $12.14 \%$ to $13.41 \%$. Previous result shows that the effect of seed delivery speed is greater that the effect of each of delivery tube length and hole span on multiples index.

\section{Factors affecting feeding index quality}

Figure (7) showed the relationship between seeds delivery speed (SDS, $\mathrm{m} / \mathrm{s}$ ) on seeds feeding index (FI, \%) under different hole span (HS, mm). The surface plot of the above relation varied due to differences in the values of independent variables (SDS, $\mathrm{m} / \mathrm{s}$ and HS, mm). Generally, (FI, $\%$ ) increased until SDS $=0.5 \mathrm{~m} / \mathrm{s}$ and after than the curve tend to decreases. The above relation were found at $\mathrm{HS}=50$ and $150 \mathrm{~mm}$ and vice versa at $\mathrm{HS}=100 \mathrm{~mm}$. It may be due to the summation of miss index (as lowest values) and seeds multiples index (as highest values) register the above trend values. The deformation of increment and decrement of FI \% at $\mathrm{SDS}=0.4 \mathrm{~m} / \mathrm{s}(86.1 \%)$ was higher than that for rate of deformation $(83.3 \%)$ at $\mathrm{SDS}=6.0 \mathrm{~m} / \mathrm{s}$. The FI \% recorded the highest values $(95.9 \%)$ at SDS of $0.5 \mathrm{~m} / \mathrm{s}$ and hole span of $150 \mathrm{~mm}$. For example by increasing the SDS 1.5 times FI \% decrement by about 0.9 times at neglect the effect of hole span.

The surface plot of feeding index (FI, \%) as affected by delivery tube length (TL, mm) for different seed delivery speed (SDS) was illustrated in figure (8). Generally, the mentioned data revealed an indirect proportion between FI and each of seed delivery speed (SDS) and tube length (TL) until the data reach to the upper limit at $\mathrm{TL}=400 \mathrm{~mm}$ and then it change his direction. For example, by increasing the delivery tube length from $300 \mathrm{~mm}$ to $400 \mathrm{~m}$ the FI increased by about 1.32 times at seed delivery speed $0.4 \mathrm{~m} / \mathrm{s}$. But by increasing delivery tube length from 400 to $500 \mathrm{~mm}$ the rate of FI decreasing by about 0.85 to times. 


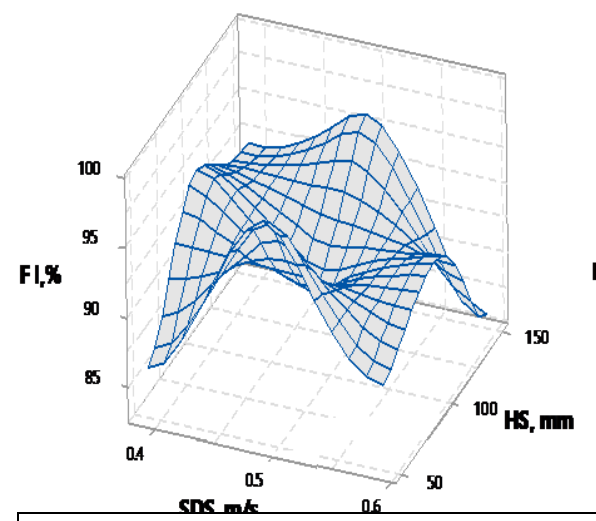

Figure (7): Surface plot of feed index vs delivery speed and hole span

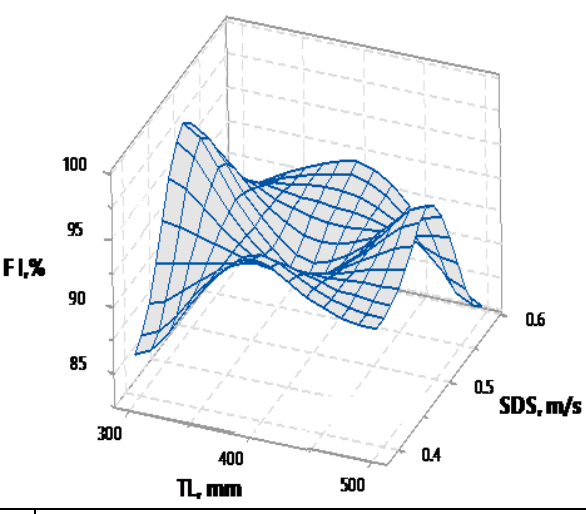

Figure (8): Surface plot of feed index vs delivery speed and tube length

The data were analysis to indicate the fit regression equations as the relationship between feed index (FI,\%) and each of seed delivery speed (SDS) and hole span (HS). The regressions were found as:

$$
\begin{aligned}
& \text { FI, } \%=86.678 * \mathrm{SDS}^{\wedge}(-0.068) \\
& \mathrm{FI}, \%=93.031 * \mathrm{HS}^{\wedge}(-0.0046)
\end{aligned}
$$

Ordinarily, Equations ( 6 and 7 ) indicated the inversely relationship between feed index (FI) and each of seed delivery speed (SDS) and hole span (HS). Also, the previous result shows that the effect of seed delivery speed (SDS) is greater that the effect of hole span (HS) on feeding index (FI).

\section{Factors affecting precision index}

The indictor of low precision means high quality and best regularity seed distribution per unit lengths (Ismail et al.- 2009 and Heege-1993). So, the response surface for the relationship between precision index (PI, \%) and seeds delivery speed (SDS, m/s) was illustrated in figure (9) under different hole span (HS). The general trend of the above relation is that by increasing the seed delivery speeds the amount of precision index decreased (PI). On the other hand, increasing the hole span (HS) increased the precision index. For example, by increasing the seeds delivery speed (SDS) from 0.4 to $0.6 \mathrm{~m} / \mathrm{s}$, the precision index (PI) decreased by about 0.32 times at hole span of $50 \mathrm{~mm}$ and by increasing the hole span from 50 to $150 \mathrm{~mm}$ the precision index increased by about 1.27 times at $\mathrm{SDS}=0.5 \mathrm{~m} / \mathrm{s}$.

Figure (10) indicated the surface plot of precision index vs seed delivery speed (SDS) and tube length (TL). From figure, the data indicated that 
the precision index (PI) decreased by increasing the (SDS) and vice versa at increase the delivery tube length. For example, at seed delivery speed of $\mathrm{SDS}=0.7 \mathrm{~m} / \mathrm{s}$ and increment TL from 300 to $500 \mathrm{~mm}$ the precision index increased by about 1.35 times.
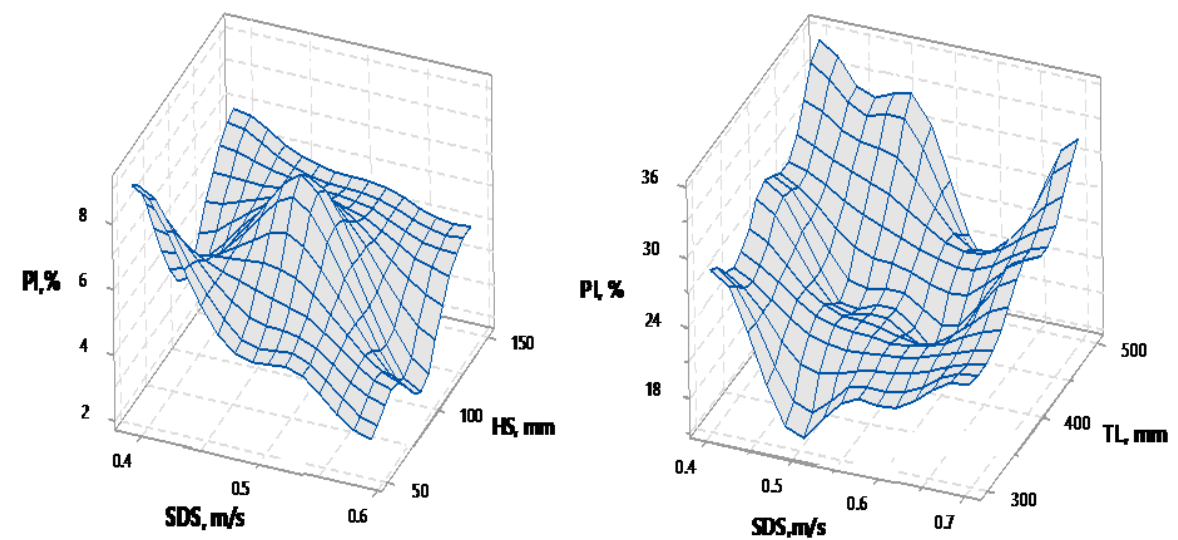

\begin{tabular}{|l|l|}
\hline Figure (9): Surface plot of precision index & Figure (10): Surface plot of precision index \\
\hline
\end{tabular} vs delivery speed and hole span vs delivery speed and tube length

The data were analysis to indicate the fit regression equations as the relationship between precision index (PI,\%) and each of seed delivery speed (SDS) Eq. 8 and hole span (HS) Eq 9. The regressions were found as:

$$
\begin{aligned}
& \mathrm{PI}, \%=19.157 * \mathrm{SDS}^{\wedge}-0.431645 \\
& \mathrm{PI}, \%=0.642 * \mathrm{TL}^{\wedge} 0.613069
\end{aligned}
$$

The fit probability analyses $(\mathrm{P})$ for equation 8 and 9 were illustrated in figures 11 and 12. From equations and figures, it easy to not that the effect of SDS $(\mathrm{P}=0.072)$ is greater than that the effect of TL $(\mathrm{P}=0.622)$ on PI.

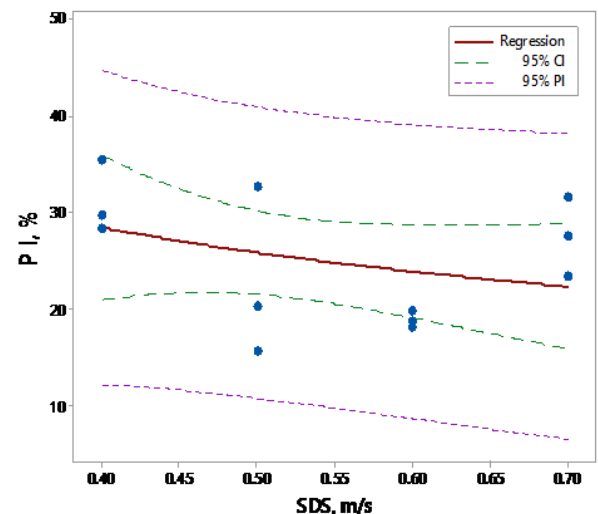

Figure (11): The fit property analyses for the relationship between PL, \% and SDS, $\mathrm{m} / \mathrm{s}$

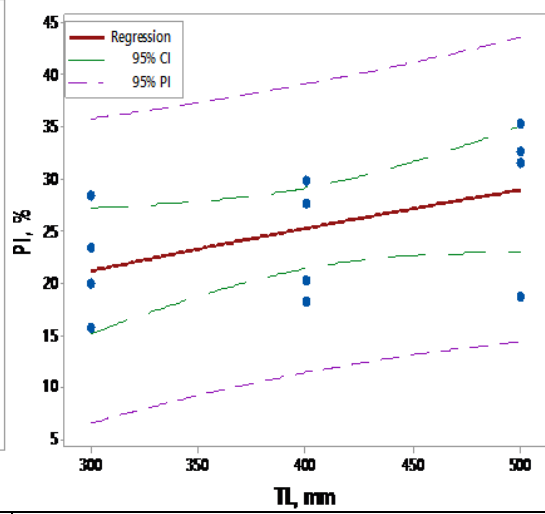

Figure (12): The fit property analyses for the relationship between PL, $\%$ and TL, $\mathrm{m} / \mathrm{s}$ 


\section{REFERENCES}

Ess, D.R.; S.E. Hawkins; J.C. Young and E.P. Christmas (2005). Evaluation of the performance of a belt metering system for soybeans planted with a grain drill. Applied Engineering in Agriculture. 21: 965-969.

Gebresenhet, G. and H. Jonsson (1992). Performance of seed drill coulters in relation to speed, depth and rake angle. J. Agric. Eng. Res. 52: 121-145.

Gratton, J.; Y. Chen and S. Tessier (2003). Design of a spring-loaded down force system for a no-till seed opener. Canadian Biosystems Engineering. 45: 29-35.

Guler, I.E. (2005). Effects of flute diameter, fluted roll length, and speed on alfalfa seed flow. Applied Engineering in Agriculture. 21: 5-7.

Heege, H.J. (1993). Seeding methods performance for cereals, rape, and beans. Transaction of the ASAE. 36: 653-661.

Ismail, Z.E. (2011). Punch planter: specification and evaluation. Misr. J. Ag. Eng., 28(4): 782-795.

Ismail, Z.E., E.H. El-Hanify and N.K. Ismail (2009). The utilization of a metering plate device for cowpea planting. J. Agric. Sci. Mansoura Univ. 34(5): 5853-5867.

Ismail, Z.E. and E.H. El-Hanify (2009). Construction and testing the seed-punch planter. Misr. J. Ag. Eng., 26(2): 597-607.

Ismail, Z.E. (2004). Developing the metering unit of the pneumatic planter "project financed by Researching Unit of Mansoura University".

Janelle, L., C. Lague and S. Tessier. 1993. Seeding tool design for no-tillage conditions in North-East. ASAE Paper No. 93-1561. St. Joseph, MI: ASAE.

Karayel, D.; M. Wiesehoff; A. Ozmerzi and J. Muller (2006). Laboratory measurement of seed drill, seed spacing and velocity of fall of seed 
using high-speed camera system. Computers and Electronics in Agriculture. 50: 89-96.

Molin, J.P.; L.L. Bashford, K. Von Bargen and L.I. Leviticus (2002). Design and evaluation of a punch planter for no-till systems. Transactions of the ASAE 41(2): 307-314.

Molin, J. P., L. L. Bashford, R. D. Grisso and A. J. Jones (1998). Population rate changes and other evaluation parameters for a punch planter prototype. Transactions of the ASAE 41(5): 12651270

Ozmerzi, A.; D. Karayel and M. Topakci (2002). Effect of sowing depth on precision seeder uniformity. Bio-systems Eng. 82: 227-230.

Ryu, I.H. and K.U. Kim (1998). Design of roller type metering device for precision planting. Transaction of the ASAE. 41: 923-930.

Sawant, S.D. (1972). Design and basic studies of a plunger-type planter. Ph.D. diss. University Park, Pa.: Pennsylvania State University.

Schueller, J.K. (1992). A review and integrating analysis of spatiallyvariable control of crop production. Fertilizer Res. 33: 1-34.

Shaw, L.N. and K.H. Kromer (1987). Revolving spade planter soil opener. ASAE Paper No. 87-1019. St. Joseph, Mich.: ASAE.

Solie, J.B. 1991. Design and field testing two ultra-narrow row grain drills. ASAE Paper No. 91-1007. St. Joseph, MI: ASAE.

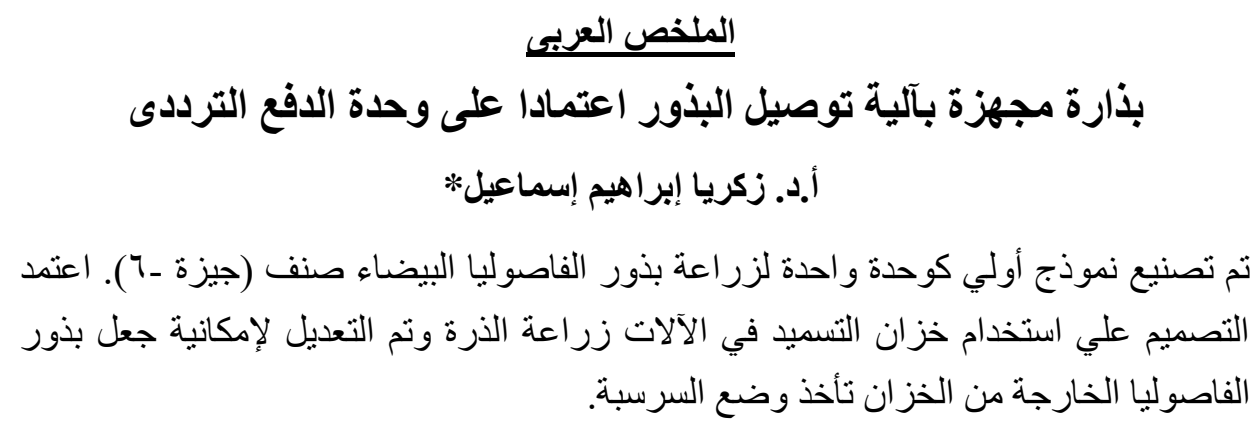

(*) أستاذ الهندسة الزراعية - كلية الزراعة - جامعة المنصورة 
تتجمع البذور الساقطة من الخزان الي وحدة التوصيل المزودة بالدافع الترددي الذي يأخذ حركته

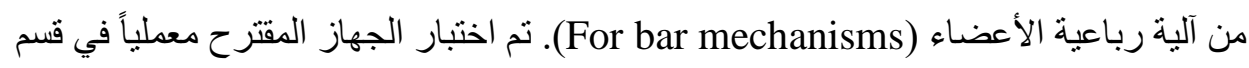

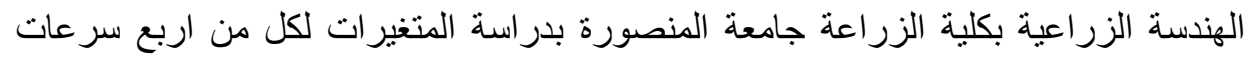

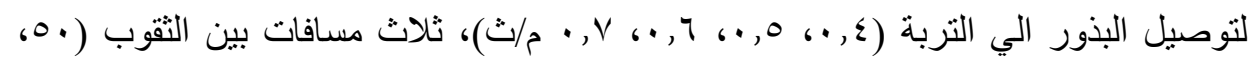

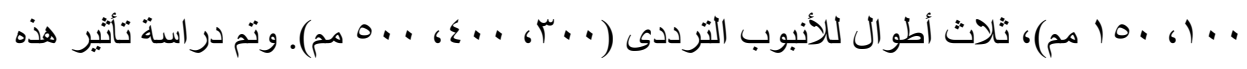

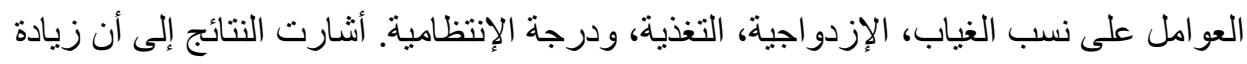

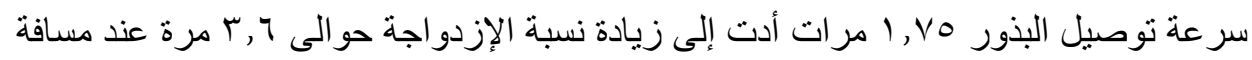

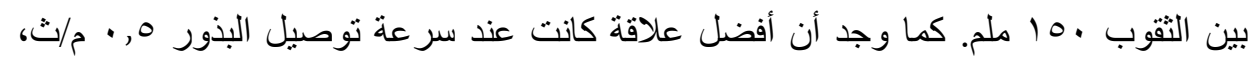

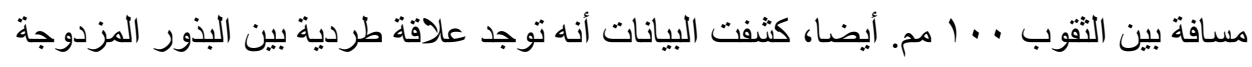
وكل من سرعة نوصيل البذور وطول الأنبوب. فى حين سجل معدل التغذية أعلى القيم

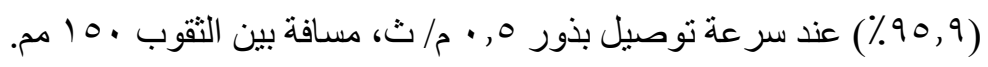

